analysis of individual behavior as scientific method cannot be denied. That, I think, was, is, and will continue to be the importance of the Journal.
Department of Psychology

Emory University

Atlanta, Georgia 30322

John A. (Tony) Nevin (Editor, 1980-1983)

\title{
VARIATION AND PROGRESS
}

Evolution, it is said, progresses by variation and selection. The same can be said of science. Scientific journals are essential components of the process, both for the individual investigator, whose experiments are not really complete until written up and submitted to the scrutiny of scientific peers, and for the research and theoretical community, which relies on the steady accumulation of archival data for its progress. The principal role of a journal is selection: to consider the variations submitted by the scientific community, and allow some, but not all, to survive as archival contributions.

When I became Editor of JEAB in 1979, I had served two terms on the Board of Editors, and had served as Associate Editor with Stan Pliskoff and Vic Laties. Thus, I had done my share of selecting. As Editor, I wanted to do something more, and made efforts to encourage variation, both in my editorials and in many conversations at ABA, APA, and EPA meetings. The results, I think, were pretty good: Of the 250 articles published during my time in office, only about half dealt primarily with fundamental topics such as stimulus control and reinforcement contingencies. The remainder explored increasingly complex stimuluscontrol problems, and relatively biological topics such as conditioned aversions, induced behavior, and foraging. Studies of human verbal and social behavior appeared in the Journal's mail, and a few of them made it into its pages. Several substantial review articles were submitted and published (one of them, by Buzsáki, invited at Vic Laties' suggestion). Quantitative analyses of schedule performance became increasingly frequent, and inspired a number of theoretical papers that summarized the data well and showed how their major features could be derived from mathematical statements of behavioral processes. The varied expertise of the Associate Editors who served with me-Ed Fantino, Lew Gollub, Phil Hineline, Andy Lattal, Stephen Lea, Eve Segal, and John Staddon-ensured fair and informed consideration of articles in virtually any area of behavior analysis. All in all, I believe that the diversity of authorship and the number and range of topics addressed by articles published in the early 1980 s increased over the previous two decades.

And this, I think, is a sign of good health. A recent article by Gould, Gilinksy, and German (1987) argued that evolutionary groups tend initially to diversify, becoming narrower only as they near extinction. If the same holds for our science, then growing diversity is a sign of health and relative youthfulness, contradicting the oft-asserted demise of behavior analysis.

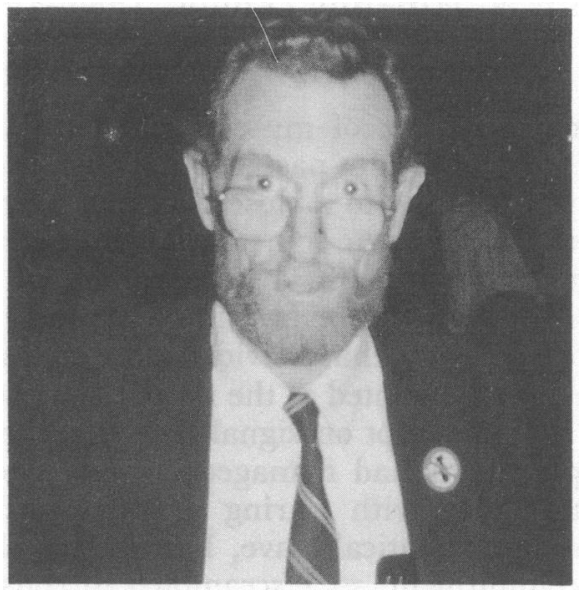

J. A. Nevin, 1986. 
There were some other respects, though, in which our field took some hard knocks during my term as Editor. Ronald Reagan was elected President, and the emphasis that his administration placed on national security shifted funds away from basic science into military research and development, with the behavioral sciences getting especially short shrift. More ominously, the Reagan administration began to talk openly about fighting and winning a nuclear war, and I became seriously concerned about the future of our species as well as our science. I have never believed that science is, or ought to be, value-free, so I wrote an editorial that tried to use behavioral terms to express concern about the growing threat of nuclear weapons. I sent it to the SEAB Board before putting it into print, and the Board split exactly in half: Some were concerned that any attempt to address political issues in JEAB's pages would weaken and ultimately destroy it, whereas others felt that the growing threat to human survival justified the use of any medium-even a scientific journal - to try to mobilize effective action. Vic Laties, with his characteristic wisdom, suggested that I recast my intended editorial as a book review that would get the issue (and my personal concern)

into the Journal's pages without appearing to represent the JEAB community; and so I did.

The last article to appear during my term was a comment on that review, by Douglas Mook, in which he argued that the prevention of nuclear war was far too serious to be approached exclusively with the traditional concepts of behavior analysis. He was right, and I was delighted to publish his piece, in part because it brought some central concepts of modern cognitive psychology into the Journal's pages, where they can be considered and analyzed productively. I think his message applies to our science as well as our survival: Behavior is too complex and too important a subject matter to be approached exclusively with any rigid set of concepts. Variation is the key to progress.

Department of Psychology

University of New Hampshire

Durham, New Hampshire 03824

\section{REFERENCE}

Gould, S. J., Gilinsky, N. L., \& German, R. Z. (1987). Asymmetry of lineages and the direction of evolutionary time. Science, 236, 1437-1441.

Philip N. Hineline (Editor, 1984-1987)

\section{SELF-CONSCIOUS BEHAVIOR ANALYSIS}

Contemplation of my editorial term lacks the charm of distant past, for that term is only just now coming to a close. My more remote personal history, though, was like those of most others, with unplanned preparation for this work through the reviewing of manuscripts. On one occasion, that provided more education than I really wanted at the time; Mike Zeiler sent a manuscript on signal-detection theory, a topic that I had managed only a nodding acquaintance with during graduate school. Being on sabbatical leave, I could not claim overcommitment, so I scrambled to comprehend a proposed merger between signal-de- tection theory and the matching law. Later, of course, I was glad to have witnessed the initial weaving of that piece of theoretical fabric. Come to think of it, that task may have been pivotal to my further involvement here, for Tony Nevin was the other reviewer for that manuscript (a public fact, since he signed his review), and soon after, he assembled a team of Associate Editors that I felt privileged to join. More generally, the most interesting and instructive part of the reviewing process came from receiving other reviewers' comments and action editors' letters. I admired the work of several Editors and Associate Editors for their pri- 